\title{
Two types of free choice universality across languages
}

\author{
Mara Panaitescu \\ University of Bucharest and University Paris 7 \\ mara.panaitescu@\|ls.unibuc.ro
}

\begin{abstract}
The paper teases apart two types of interpretations displayed by so-called "universal" free choice (FC) determiners (e.g., French n'importe quel or Spanish cualquiera) depending on the kind of licensing environment they are placed in, which will be called parallel and serial universality respectively. Since serial universal readings are available to all FCls cross-linguistically and the only possibility in some cases, they are taken to be the central semantic ingredient of free choice. Section 2 aims to establish a parallel between serial universality (particularly subtrigged sentences) and other constructions which involve semantically constrained pairs of events. The third section represent the co-variation of entity, event and world indices as an option that determiners have under certain (syntactic and semantic) conditions, and which FCls have grammaticalized. The other ingredient which singles out serial universality from other event-related readings is the (non-optional) causal link between the events introduced by the relative clause and matrix events. The link between relative clause and matrix events is analyzed as a form of historical necessity, a relation between cause and effect, as understood within a metaphysical modal base.
\end{abstract}

Keywords: subtrigging; serial universality; parallel universality; event related reading; causation

\section{Introduction}

\subsection{Introducing parallel and serial universality}

The label of "universal" FCIs for English any (Kadmon \& Landman 1993; Horn 2000; 2005; Dayal 1998; 2013), French n'importe quel (Jayez \& Tovena 2005) Romanian orice (Farkas 2006), Spanish cualquiera Menendez-Benito (2005), Catalan qualsevol (Quer 1998), Greek opjosdhipote (Giannakidou 2001; Giannakidou \& Cheng 2006) is used to set them apart from "existential" FCIs, such as French un NP quelconque (Jayez \& Tovena 2006) or Romanian un NP oarecare (Farkas 2006). Regarding the status of "universal" FC determiners, all accounts of free choice speak about the universal readings or universality effects, but not all of these assume that FCIs are universal quantifiers. Besides the double status as FCI and NPI of these items in some languages (including Engl. any, see Haspelmath 1997 for other languages), in certain contexts these items seem to pattern 
closer to existential indefinites than to universal quantifiers. For instance, (1a) seems to come closer in interpretation to (1b) than to (1c):
(1) a. Push any button!
b. Push a button!
c. Push every button!

The same is true for the possibility modal below, both in its deontic (2a) and its epistemic use (2b). The permission to take any apple seems closer in meaning to the permission to take one apple. At most, it may be further extended to mean 'one or more', but not a permission to take all of the apples but no less than that (which is what You may take every apple presumably conveys).

(2) a. You may pick any apple/an apple/every apple.

b. John may be anywhere/somewhere/\# everywhere in France right now.

On the other hand, in other contexts, FCIs are more similar to universal quantifiers, (since (3a) is closer in meaning to (3b) than to (3c)):

(3) a. John talked to any student who approached him.

b. John talked to every student who approached him.

c. John talked to a student who approached him.

The kind of sentence exemplified in (3a) above has been called "subtrigged" (LeGrand 1975) because the presence of the relative clause seems to function as a saving mechanism for the FC determiner. Other cases in which the FCI is more readily paraphrased using a universal quantifier are generic sentences, comparatives and ability modals:

(4) a. Any owl hunts mice.

b. John is faster than any other athlete.

c. These juicer machines (can) crush any fruit.

In the following discussion there will be no commitment as to how the universality effect comes about - directly, if the FCI is taken to be a universal quantifier, or indirectly, if one takes it to be an indefinite with some sort of maximality constraint (Farkas 2006) or some associated implicature which brings about the maximality effect as in Chierchia (2013). Nevertheless, at least if we take things at face value, it will become apparent by the end of the discussion that free choice determiners may be either of 
the two: French tout and Japanese wh-demo appear to be non-symmetrical quantifiers, English any and French n'importe quel seem to be indefinites. Moreover, certain languages dispose also of free choice free relatives, which have been taken to be definites by some (Tredinnick 2005; Hinterwimmer 2008). ${ }^{1}$ Thus, all three DP types - definite, indefinite, universally quantified - seem to be compatible with universal free choice.

The term universality will be employed in the sense of "universal reading" or "universal/maximality effect". In this sense, I will talk about two types of universality - parallel and serial, exhibited in (1a) and (3a) respectively. As the label suggests, in the case of parallel universality, each accessible world corresponds to a unique eventuality that satisfies the VP condition, with the entity variable marked with free choice maximally covarying across worlds (one pushed button for (1a), with all buttons being pushed in some world or other). In the case of serial universality, each accessible world will verify the NP and VP conditions on the entire NP set. Since the NP set comes with an event variable, one can say that maximality applies to event-entity pairs in each world. This "double universality" all approaching students in all worlds were such that John talked to them is nevertheless time-bound, i.e., all entities that were approaching students within the reference interval.

\subsection{Two types of FCls}

Assuming that serial universality is available cross-linguistically, while parallel universality is an option for some items but not others, one may produce a typology of FCIs. Given this, and also that serial universality is observable in subtrigged sentences (the only environment where there is no identifiable licensor for the FCI), I will assume that serial universality is the central FC strategy and that subtrigged sentences are the key to deciphering the semantic contribution of FCIs.

(5) Two types of FCIs cross-linguistically:

a. CLASS I: FCIs that display parallel + serial universality: i.e., Rom. orice, Fr. n'importe quel, English FC any, Spanish cualquiera, etc.

b. CLASS II: FCIs that display only serial universality: i.e., Fr. tout Swed./Norw. wh-som helst, Jap. wh-demo.

${ }^{1}$ Maximality is an evaluation constraint for FCIs but a local operation on the domain of enitities for definites. That is, in You may take the apples, the definite determiner picks out the maximal set of apples in the NP set, after some contextual restriction has applied (say, the apples in this basket). 
To illustrate with the two FCIs in French, (6) contrasts with (7) in that the NP carte is not eventive, while délit is. Tout is sensitive to this distinction, while n'importe quel is not.

(6) Prends n'importe quelle carte/ ${ }^{\#}$ toute carte. take NIMPQ card TOUT card

'Take any card.'

(7) Punis n'importe quel/ tout délit. punish NIMPQ TOUT misdemeanor

'Punish any misdemeanor.'

A closer look will indicate that tout is acceptable in serial universality contexts (e.g., past habitual imperfective sentences, generics, subtrigged sentences and ability modals), and excluded from parallel universality contexts.

(8) Tout étudiant qui a triché a été renvoyé

'Any student who cheated was excluded'.

As suggested in Jayez \& Tovena (2005), tout requires domain shift over the set introduced by the noun. In (7) and (8), the set of misdemeanours/cheating students is not stable across worlds (compare with Push any button!, where the same set of buttons is available for choosing in all the alternative worlds). Domain shift is obtainable in two ways: either the noun is eventive, as in (7), or the FC expression contains an eventive relative clause, as in (8). For the present purposes, domain shift is a useful descriptive tool for singling out serial universality.

It is important to mark that if clauses do not by default induce serial universality. To illustrate this with the Romanian FCI orice (and English any), the default use of the conditional (9a) below illustrates a parallel universal environment:

(9) a. Dacă ai orice problemă, sună-mă.

if have-2SG ORICE problem call-me

'If you have any problem, call me.'

b. Dacă mănânci orice fel de dulciuri, vei avea probleme de greutate.

if eat.2SG ORICE kind of sweets will.2SG have problems of weight

'If you eat any kind of sweets, you will have weight problems.'

In $(9 \mathrm{~b})$, on the other hand, it can be safely assumed that there is an extra source of modality, be it a covert habitual or dispositional operator, 
and it is this operator which is responsible for serial universality. What is important to retain is that, in contexts like (9a), class II FCIs are not felicitous. This is what Jayez and Tovena (2005) report for the French translation of (9a) with tout (their example (4b), given below).

(10) ${ }^{\#} \mathrm{Si}$ tu as tout problème téléphone-moi.

if you have TOUT problem phone-me

Scandinavian FCIs seem to follow the same pattern, as reported in Sæbø (2001) (Norwegian example (53)).

(11) a. Om du vil ha en vare, må du betale vor den.

if you will have a ware must you pay for it

'If you want a commodity, you must pay for it.'

b. ${ }^{\#} \mathrm{Om} \mathrm{du}$ vil ha en hvilken som helst vare, må du nbetale vor den.

if you will have a which as rathest ware must you pay for it

These FCIs are nevertheless perfectly acceptable in subtrigged sentences. This seems rather puzzling, given that subtrigged sentences have been assumed to involve some kind of covert conditional structure.

Moving on to a different FCI, which also seems to exhibit only serial universal readings, Japanese wh-demo is even more puzzling since it seems to override a constraint which has been taken to be essential for FCI licensing, namely the presence of some form of overt or covert modality.

(12) Kinoo John-wa dono hon-demo yon-da.

yesterday John-TOP which book-DEMO read-PAST

'John read any book yesterday (indiscriminately).'

According to Nakanishi (2017), there is an at-issue predicate in the restriction of demo, which works like a subtrigger. The interpretation of (12) is then: for all book situations which are at issue, John read that book/those books. This is a case of serial universality since all relevant books in all worlds are considered. In all contexts in which class I FCIs allow for an existential interpretation wh-demo is universal.

(13) John-wa sankoobunken-no dono hon-demo yom-anebanaranai.

John-TOP reference-GEN which book-DEMO read-must

'John must read any of the books in the reference.'

The English translation, to the extent that it is felicitous, favors an interpretation in which John must pick one book and read it. The Japanese 
version on the other hand is universal: John must read the book(s) which may at some point be considered relevant. It just is not yet established which books are in the reference, which corresponds to the modal variation generally associated with FCIs. If the existential reading is the only pragmatically appropriate one, wh-demo is infelicitous:

(14) ?'Tuzukeru-ni-wa dono kii-demo osite-kudasai. continue-to-TOP which key-DEMO press-please

Nakanishi (2017) proposes that wh-demo obeys an iterativity constraint. I will refer to it as serial universality in the following section.

Turning back to the two types of universal FCIs under discussion (illustrated by Romanian orice, French tout and Japanese wh-demo respectively), the hypothesis put forth here is that the "core" universal FC meaning is represented by tout and amounts to a correlation between world, event and individual indices as in (15a). This is marked as a subscript $\langle w, e, x\rangle$, in which $w$ is a variable of type world, $e$ is a variable of type event, an $x$ is an entity type variable. All "universal" FCIs display the core meaning; in the case of tout, it is the only option. Romanian orice further allows the version in $(15 \mathrm{~b})$, where the event variable is specified as being uniquely instantiated. This option is activated in the types of contexts commonly referred to as "existential readings", such as imperatives of the sort Push any button or sentences with permission modals such as You may read any book). The Japanese FCI allows for the version in (15c), where $e_{c}$ stands for context-provided set of events, that is, it involves context-dependent domain shift, but it does not have the b(i) option:

(15) $\forall$-FCI

a. Core meaning: $\mathrm{FC}_{\langle w, e, x\rangle}$

b. Allowed versions:

(i) $\mathrm{FC}_{\langle w, ! e, x\rangle}$ : orice, n'importe quel, any

(ii) $\mathrm{FC}_{\left\langle w, e_{c}, x\right\rangle}:$ wh-demo

The following section presents other linguistic phenomena which have one or more properties in common with subtrigged sentences, with the purpose of offering, in section 3, a more detailed account of serial universality. 


\section{Similar semantic phenomena: relations between events}

In order to reach a descriptively accurate characterization of the kind of relation involved between events in subtrigged sentences, it is useful to look at other linguistic phenomena which involve pairs of related events. Section 2.1 presents some properties of every time sentences and a sketch of Rothstein's (1995) account involving a matching function. Section 2.2 is allotted to sentences with definite plurals/singular indefinites with a relative clause that display QVE effects, as discussed in Hinterwimmer (2008) andEbert \& Hinterwimmer (2010). Subsection 2.3 is dedicated to Doetjes \& Honcoop's (1997) extension of Krifka's (1990) account of event-related cardinals onto constructions with non-symmetrical quantifiers modified by relative clauses. Section 2.4 presents the semantics of because clauses, as analyzed in Kratzer (1997). At each point, I will pursue the comparison in terms of associated semantic effects between each of these phenomena and subtrigged sentences.

\subsection{Every time sentences}

\subsubsection{Semantic properties of every time sentences - Rothstein (1995)}

Rothstein (1995) analyzes the following types of sentences involving adverbial adjuncts, henceforth every time sentences: ${ }^{2}$

(16) a. I regretted it every time I had dinner with John.

b. Every time the bell rings, Mary opens the door.

The interpretation of these sentences can be expressed informally in the following terms: in (16a), it must be the case that there are at least as many regret events as there are dinner events. In (16b), there are at least as many door opening events as there are bell ringing events. The difficulty in formalizing such sentences is that they seem to convey more than that for every $e$ there is an $e^{\prime}$. This paraphrase (or its formalization involving universal quantification) does not capture the fact that the values for $e^{\prime}$ are necessarily distinct across assignments. By contrast, universal quantification over entities allows just that. Taking an example such as Every girl saw a film, even though the indefinite is interpreted as having narrow

${ }^{2}$ Sentences with complement clauses (I regret every time I had dinner with John) are not captured by the account and display clearly observable semantic and syntactic differences. It is crucial for Rothstein's analysis that every time sentences are adjuncts headed by a silent preposition. 
scope with respect to the universal quantifier, it may happen that the same film was watched by two different girls. That means it is not necessary for there to be as many films as there are girls. In a nutshell, Rothstein captures this additional restriction via a matching function which operates to the effect that every regretting event is mapped onto a dinner event.

An interesting thing to observe is that in the case of every time sentences, the tenses of the two clauses must match, as shown below:

(17) a. I regret it every time you $\mathrm{do} /{ }^{*} \mathrm{did} /{ }^{*}$ will do that.

b. I meet a friend every time I go $/{ }^{*}$ went $/{ }^{*}$ will go to the bakery.

What is also relevant for our present purposes is that the noun time in every time sentences ranges over events, not time intervals, and every time sentences relate pairs of events proper (not states, propositions/cases/states of affairs). Regarding this aspect, Rothstein draws attention to the following contrast between what Lewis (1975) called adverbial quantification over cases (18) and every time sentences (19):

(18) a. Always, when a man owns a donkey, he is fond of it.

b. Every man who owns a donkey is fond of it.

c. Always, when a quadratic equation of this sort has a solution, it is positive.

(19) a. *Every time a man owns a donkey he is fond of it/he gives it carrots/he has to pay donkey tax.

b. *Every time a quadratic equation of this sort has a solution it is positive.

Stative predicates are not allowed in every time sentences, unless they are interpreted as being stage-level:

(20) a. Every time John is sick, he goes to the doctor.

b. Every time Bill is in love, he is unbearable.

c. *Every time Bill is tall, he can reach the cupboard.

d. ?'Every time Mary is red-haired, she looks great.

As mentioned above, the matching function is, according to Rothstein, supplied by a silent preposition and is left semantically underspecified. Even though tense restrictions were observed, and these might be considered to be somehow related to this function, no particular causal link or temporal ordering is required. In (21) below and many other cases, the link seems to be causal and not merely temporal:

(21) Every time my mother asks me to visit, I go. 
However, examples can be produced where there is no causal connection, not even temporal ordering:

(22) a. I resent it every time I have/*had dinner with him.

b. Every time Bill buys a donkey, John sells one.

As Rothstein points out, the resenting and the selling can be before, after, or simultaneous with the event of the adverbial. Also, the existence of any explanatory relation between the events is not a requirement, since the following comment is perfectly natural:

(23) Isn't it funny - it always turns out that every time Bill buys a donkey John sells one, yet there clearly isn't any connection.

\subsubsection{Comparison with subtrigging}

When trying to pursue a comparison with subtrigging, it is clear that there are at least certain similarities. Intuitively, both constructions involve some form of matching that precludes the same matrix event from being paired with two every time events/FC events.

(24) a. Every time I went to the bakery, I met John.

b. Any student who cheated received a penalty.

In (24a), it cannot be that there are three events of going to the bakery, but only two events of meeting John. In (24b), it cannot be that a student cheated twice but was punished only once.

Secondly, no states are allowed in subtrigged sentences. (25a) below seems to be acceptable to the extent that it's reinterpreted as every child who fell sick, while (25b) is much harder to accommodate into a meaning such as prove one's intelligence.

(25) a. Any child that was sick was taken to the infirmary.

b. ?The school gave a prize to any child that was intelligent.

As for the constraint on tense, the tense of the two clauses must match in the case of every time sentences, but not in the case of subtrigging:

(26) a. *Every time a student cheated, he will be punished.

b. For every student who cheated, some form of punishment will be applied.

c. Any student who has cheated (in yesterday's exam) will be punished. 
Looking at (26a) there is no reason why it could not happen that past cheating events will lead to different future punishing events, yet every time sentences cannot be used to express this. Constructions which resemble Boolos's $(1981)^{3}$ sentences as in (26b) do seem to be allowed tense mismatches, but these constructions are the most permissive in their distribution, since they allow quantification over cases. (26c) is acceptable, but only in the context of talking about school regulations.

What the pairing of events in subtrigged sentences requires is a temporal sequence, with the relative clause events preceding the matrix events. Assuming a scenario in which travellers leave from point $\mathrm{A}$ at different times and it takes them four days to arrive at point B:

(27) a. ? Any traveller who will arrive tomorrow left the day before yesterday.

b. If a traveller will arrive tomorrow, they left the day before yesterday.

c. Whoever arrives tomorrow left the day before yesterday.

Even if there seems to be some indirect explanatory link between the two events, the subtrigged sentence cannot range over pairs of events where the relative clause event occurs after the matrix event, as shown in (27a). By contrast, the if clause (27b) and free choice free relative (27c) counterparts are perfectly natural. What the infelicity of (27a) also shows is that the explanation connecting the events cannot be understood epistemically, as it can in the case of $(27 \mathrm{~b})$ and $(27 \mathrm{c})$, which are presumably interpretable as saying that if a traveller arrives tomorrow, we will be able to conclude that they left the day yesterday.

All the remarks above point to the major distinction between the matching function involved in every time sentences and the connection between events within subtrigged sentences: the latter is a causal connection. The one-to-one pairing effect observable in subtrigged sentences will be captured in section 3 by virtue of the definition of causation as holding uniquely in each world.

\subsection{QVE effects with DPs containing relative clauses}

\subsubsection{The tense agreement constraint and the causal override - Hinterwimmer (2008)}

Hinterwimmer (2008) and Ebert \& Hinterwimmer (2010) provide the following data to argue that adverbial quantifiers like usually bind situation

${ }^{3}$ Rothstein (1995) includes these kinds of sentences in the matching function analysis, also accounting of course for the differences from every time sentences. 
variables (and not also individual variables), unlike quantificational determiners like most, which range over entities. Plural definites and singular indefinites can display QVE effects when bound by the frequency adverb, ${ }^{4}$ but also display certain tense constraints which are not present in paraphrases employing quantificational determiners.

(28) a. The people who lectured at the conference last summer were usually Japanese.

b. Most (of the) people who lectured at the conference last summer were Japanese.

a. ${ }^{*}$ The people who lectured at the conference last summer are usually Japanese.

b.' Most (of the) people who lectured at the conference last summer are Japanese.

(29) a. A man who studied linguistics in the eighties was usually blond.

b. Most men who studied linguistics in the eighties were blond.

a. '? A man who studied linguistics in the eighties is usually blond.

b.' Most men who studied linguistics in the eighties are blond.

The relevant contrast can be observed if there is a tense mismatch between relative and matrix clause. The adverbially quantified sentence is sensitive to this dimension (cf. (28a) vs. $\left(28 \mathrm{a}^{\prime}\right)$ and $(29 \mathrm{a})$ vs. $\left(29 \mathrm{a}^{\prime}\right)$ ), while the quantificational determiner is not (cf. $(28 b)$ and $\left(28 b^{\prime}\right),(29 b)$ and $\left.\left(29 b^{\prime}\right)\right)$. Whether this is conclusive evidence regarding the semantics of usually as a situation binder is beyond the scope of this paper. It is interesting to inquire why the tense matching between matrix and relative clause is ever relevant in the felicity of sentences. ${ }^{5}$

The explanation Hinterwimmer provides for the presence of a tense agreement constraint on adverbs is pragmatic and is expressed within a situation semantics framework. In a nutshell, the adverb introduces an implicit context variable in its restriction, which determines the range of situations quantified over. The C-variable $s$ needs to be temporally located, and in the case of $\left(29 \mathrm{~b}^{\prime}\right)$, this is done indirectly, by resorting to the temporal specification in the eighties of situation variable $s^{\prime}$ on the predicate study in the relative clause. But, the $\mathrm{C}$-variable $s$ and the relative clause situation $s^{\prime}$ are also included in the nucleus of the quantifier. In the nucleus, the situation $s^{\prime \prime}$ is introduced by the main predicate blond, and constrained in

${ }^{4}$ Suitable examples were provided, in which the matrix verb is stative and precludes the adverb from quantifying over stages of individuals.

${ }^{5}$ To anticipate, even sentences such as (28b) and (29b) have an event related reading, which the tense mismatch in $\left(\mathrm{b}^{\prime}\right)$ excludes. That is, in $(28 \mathrm{~b}) /(29 \mathrm{~b})$, one can count people/men multiple times if they lectured at the conference/studied linguistics more than once, but not so in $\left(28 \mathrm{~b}^{\prime}\right) /\left(29 \mathrm{~b}^{\prime}\right)$. See section 2.3 for discussion. 
the same time to overlap with speech time and be included in $s^{\prime}$, which leads to contradiction. On the other hand, if an adverbially quantified sentence is meant to express a causal relation (and can naturally receive such an interpretation), Hinterwimmer observes that the tense agreement constraint can be overridden:

(30) A man who studied linguistics in the eighties is usually competent.

\subsubsection{Comparison with subtrigged sentences}

In the following, the examples of subtrigged sentences will be in Romanian, since one of the goals of this subsection is to tease apart tense agreement constraints from aspect agreement constraints.

Looking at subtrigged sentences containing stative predicates, it is important to point out two things. Firstly, the causal link must always be present to the effect that states such as be blond can never be accepted, even when there is a tense match:

$$
\begin{aligned}
& \text { *?? Orice român care a studiat lingvistică în anii } 80 \text { era blond. } \\
& \text { ORICE Romanian who has studied linguistics in years.DEF } 80 \text { was.IMPF blond } \\
& \text { 'Any Romanian who studied linguistics was blond.' }
\end{aligned}
$$

But the sentence is unacceptable for another reason as well. Removing the issue of finding a causal link, one discovers an aspectual constraint (not observable in English but observable in Romanian). ${ }^{6}$

(32) ?"Orice român care a studiat lingvistică în anii $\quad 80$ era $\quad$ competent. ORICE Romanian who has studied linguistics in years.DEF 80 was.IMPF competent

'Any Romanian who studied linguistics was competent.'

The relative clause is marked with perfective aspectual morphology, while the matrix clause is marked with imperfective and the sentence remains degraded. ${ }^{7}$ Compare with:

${ }^{6}$ A similar contrast was observed in Italian when clauses by Lenci and Bertinetto (2000). A note in passing: Ferreira (2016) proposed an $R$ relation between the events in the when-clause and the events in the matrix clause, where $R$ can stand for either temporal co-incidence or a causal link.

${ }^{7}$ Substituting the imperfective with a perfective such as a fost competent 'has been competent' unambiguously yields the eventive interpretation: after studying linguistics, those individuals did something to prove themselves competent. This is expected in the present analysis. 
(33) Orice român care studia lingvistică în anii 80 era competent. ORICE Romanian who studied.IMPF linguistics in years.DEF 80 was.IMPF competent 'Any Romanian who studied at the faculty of linguistics was competent.'

The reason for revealing this aspectual constraint is to rule out apparent counterexamples to the claim that subtrigged sentences involve a causal link between events. The final goal of this paper is to characterize subtrigged sentences, understood as those types of constructions which, in the absence of free choice morphology, would be interpreted as non-modalized and episodic. In Romanian, these sentences involve perfective morphology. As for the imperfective versions such as (33), they are left as a separate object of inquiry, since imperfective aspect encodes not only temporal information, but also involves some modal component (see Deo 2009; Ferreira 2016 and references therein) which intervenes as a factor in the licensing of free choice determiners. The presence of an eventive component in the free choice DP is no longer a prerequisite if the main verb is imperfective. Hence, the following sentence is perfectly felicitous in Romanian without a relative clause modifying the NP Romanian:

(34) Orice român $\quad$ studia/ era $\quad$ competent în lingvistică în\} anii 80 . ORICE Romanian studied.IMPF was.IMPF competent in linguistics in years.DEF 80 'Any Romanian \{studied/was competent in\} linguistics in the eighties.'

Leaving aside the differences between Hinterwimmer's usually sentences and subtrigged sentences, the QVE sentences in (28) and (29) were discussed because they illustrate a linguistic phenomenon in which temporal and aspectual matching constraints are not predictable if one takes the semantics of relative clauses and the semantics of frequency adverbs in isolation. In the case of subtrigging, one can find aspectual matching effects, as well as temporal restrictions (the relative clause event must precede the main clause event), and these effects are arguably the result of the interaction between free choice morphology and the event structure of these sentences.

\subsection{Event-related readings}

\subsubsection{How to get event related readings of non-symmetric quantifiers - Doetjes and Honcoop (1997)}

Doetjes and Honcoop (1997) offer an account of the ambiguity of sentences such as (35), first analyzed in Krifka (1990): 
(35) Last year, 4,000 ships passed through the lock.

a. Object-related (OR) reading: 4,000 ships are such that each of them passed through the lock last year.

b. Event-related (ER) reading: there were 4,000 events in which a ship passed through the lock last year.

A first remark is that only certain determiners ${ }^{8}$ allow for OR reading, more specifically symmetric quantifiers. Strong quantifiers like most disallow ER:

(36) Last year, most ships passed through the lock.

a. OR: most ships are such that each of them passed through the lock last year.

b. ER: *most events in which a ship passed through the lock (last year) occurred last year.

Nevertheless, if the non-symmetrical quantifier has an eventive relative clause in its restriction, the ER reading emerges:

(37) Most ships that passed through the lock transported radioactive waste.

a. OR: most ships that passed through the lock are such that each transported radioactive waste.

b. ER: most events in which a ship passed through the lock were events in which a ship transported radioactive waste.

ER readings of non-symmetrical quantifiers with a relative clause occur under certain conditions. First, both the relative clause and the matrix predicate must be eventive. In case an individual level predicate is used, it is reinterpreted as being stage level:

(38) a. Most ships that passed through the lock have a red mast.

(only OR)

b. Most ships that passed through the lock had a red mast.

$(\mathrm{OR} / \mathrm{ER})$

ER is available only for (38b), where the effect of using past tense is arguably a reinterpretation of the matrix predicate as being stage-level. The ER interpretation may be paraphrased as: most events in which a ship passed through the lock were events in which a ship was observed to have a red mast. Furthermore, notice that the main verb must agree in tense with the verb in the relative clause. This happens in all cases, not only with ILPs:

(39) Most ships that passed through the lock are now in the port.

(only OR)

${ }^{8}$ The authors treat all determiners as quantifiers, following Barwise \& Cooper (1981). 
The authors conclude that in order for the ER reading to occur, the relative clause and matrix events cannot be independent from one another. For instance, in (37) on the (b) interpretation, the events of transporting radioactive waste must coincide with events of passing through the lock. It cannot be that the ships passed through the lock last year and transported radioactive waste yesterday. For the OR, on the other hand, this interpretation is available and it can be made explicit by adding last year and yesterday to the relative clause and matrix VP of (37).

\subsubsection{Comparison with subtrigged sentences}

First of all, there are certain similarities between ER sentences with asymmetrical quantifiers containing a relative clause and subtrigged sentences, having mainly to do with the temporal and causal connections between events. FCIs which only display serial universality like tout will be analyzed in the following section as ranging over entity, event and world variables. Having an eventive relative clause in the restriction is of course always an option for symmetric quantifiers (cf. Many ships that passed through the lock transported radioactive waste), in which case, on the event-related reading, one counts pairs of events. The same mechanism is presumably behind subtrigged sentences in the case of class I FCIs.

As a preview for the following discussion, the cases of serial universal free choice readings will be identified in a parallel fashion to the ER readings of non-symmetrical quantifiers. One might call them obligatory WER sentences. A difference is that the series of relative clause and matrix clause events are not only temporally dependent, but also world-dependent, i.e., they are causally linked. Another difference is that we will assume that FCIs obligatorily range over objects, worlds and events, such that there is no counterpart of the OR reading that most exhibits.

\subsection{Causal explanations}

Subtrigged sentences express non-accidental regularities, which indicates that they share certain properties with causal explanations in the sense of Kratzer (1997).

\subsubsection{Two readings associated with because: Kratzer (1997)}

Kratzer (1997), building on Davidson (1967), distinguishes between two possible interpretations of sentences expressing causal relations between two propositions. Intuitively speaking, the two interpretations differ in 
whether some material in the sentence is relevant in establishing the causal link between the two clauses. The kind of information that is conveyed by this material might be called a reason or explanation for the causal link. Thus, simple causation (or causation by contingency) is different from causal explanation in that it does not provide the actual reason for the occurrence of some effect, just the causing event itself. This seems to indicate that the cause relation holds between events (as opposed to propositions). Causal explanations, on the other hand) state that two events that have certain properties are causally related in virtue of having those properties.

(40) a. I fell because the principal did.

b. I went to the pageant because the principal did.

(40a) evokes a scenario where the principal was walking behind me, fell, and knocked me down as well. It is an instance of simple cause. (40b) on the other hand implies that the fact that the participant in the second event is the principal is somehow relevant for my going to the pageant. If that same person had held a different position, I might not have gone to the pageant just because he did.

Kratzer argues that both readings are available in general in because sentences (i.e., there are not two separate meanings associated with because), with one or the other being more prominent. The ingredients which provide the correct interpretations are: the notion of minimal situations exemplifying a proposition; the assumption that all predicates have a situation argument; the assumption that this situation argument can be evaluated with respect to situations other than the current evaluation situation. The formalization is expressed in a translation of Davidsonian event semantics within a situation semantics.

\section{(41) Eventualities that exemplify propositions (Kratzer's (33))}

If $s$ is any possible situation and $p$ any proposition, then $s$ is an eventuality that exemplifies $p$ iff for all $s^{\prime}$ such that $s^{\prime} \leq s$ and $p$ is not true in $s^{\prime}$, there is an $s^{\prime \prime}$ such that $s^{\prime} \leq s^{\prime \prime} \leq s$, and $s^{\prime \prime}$ is a minimal situation in which $p$ is true.

According to Kratzer, because clauses do double duty: they provide descriptions for events and state a counterfactual relationship between propositions. They thus combine the features of both opaque (causal explanation in (42a) below) and transparent because (simple cause in (42b) below). Spelling this out, we would get the following two representations: 
(42) a. I went to the pageant because a friend of mine did.

b. Causal explanation:

$\lambda w \exists e_{1}\left(e_{1} \leq w \& \downarrow \lambda s\right.$ (went $_{s}$ to the pageant (you)) $\left(e_{1}\right) \&$

$\exists e_{2}\left(e_{2} \leq w \& \downarrow \lambda s \exists x\right.$ (friend of mine $_{s}(x) \&$ went $_{s}$ to the pageant $\left.(x)\right)\left(e_{2}\right) \&$ because $_{w}\left(\lambda s\right.$ (went $_{s}$ to the pageant (you)), $\lambda s \exists x$ (friend of mine $s(x)$ $\&$ went $_{s}$ to the pageant $\left.\left.\left.(x)\right)\right)\right)$ )

c. Simple cause:

$\lambda w \exists e_{1}\left(e_{1} \leq w \& \downarrow \lambda s\right.$ (went $_{s}$ to the pageant (you)) $\left(e_{1}\right) \&$ $\exists e_{2}\left(e_{2} \leq w \& \downarrow \lambda s \exists x\right.$ (friend of mine $_{s}(x) \&$ went $_{s}$ to the pageant $\left.(x)\right)\left(e_{2}\right) \&$ because $_{w}\left(\lambda s\right.$ (went $_{s}$ to the pageant (you)), $\lambda s \exists x$ (friend of mine $e_{2}(\boldsymbol{x}) \&$ went $_{s}$ to the pageant $\left.\left.\left.(x)\right)\right)\right)$ )

(42a) accounts for the non-specific interpretation of a friend of mine (the causal explanation or opaque version). It says that there is an event $e_{1}$ which exemplifies a set of situations $s$ such that I went to the pageant in $s$ and there is an $e_{2}$ which exemplifies situations $s$ in which there is some friend of mine $x$ in s such that $x$ went to the pageant in $s$ and the set of situations $s$ such that I went to the pageant in $s$ are in a because relation to a set of situations $s$ in which there is an $x$ such that $x$ is a friend of mine in $\boldsymbol{s}$ and $x$ went to the pageant in $s$. Basically, the opaque reading comes about because the identity of the friend co-varies with the situations.

To get the simple cause reading, one only needs to index a friend of mine within the because relation to some other situation index than the local $s$. In (42b) above, the minimal difference from (42a) is that $x$ is a friend of mine in $\boldsymbol{e}_{2}$, the actual event of some friend of mine going to the pageant.

Kratzer concludes that there is only one because. The indefinite (or definite, for instance, the principal in (40)) is the culprit for the apparent ambiguity, an instance of (intermediate) pseudoscope.

\subsubsection{Comparison with subtrigging}

There are certain common semantic properties of because sentences and subtrigged sentences. First of all, the NP description modified by the relative clause seems to always be relevant in the causal connection. In other words subtrigged sentences seem to always induce opaque interpretations of the causal link (causal explanations). Examples of accounts on free choice which attempt to capture this intuition are Dayal (1998) and Farkas (2006), which assume that free choice DPs come with a situation index.

Yet, there are reasons for which Kratzer's analysis of because and Dayal's application to FCIs does not seem compatible with the underlying mechanism responsible for subtrigging. First of all, as has been repeatedly 
stated, subtrigged sentences only connect pairs of events. Because clauses are not so constrained in this respect. (43) exemplifies a case in which the reason is non-eventive.

(43) The students went to the pageant because they need credits.

These two scenarios cannot be expressed with a subtrigged FCI. It may not be surprising that the main verb in subtrigged sentences has to be eventive. We could take this to be assumed by definition. But the fact that the free choice NP is obligatorily eventive and obeys temporal sequence constraints is in need of an explanation.

\subsection{Conclusion}

Subtrigged sentences relate pairs of events, like every time and when sentences. They are modalized, like because clauses and free choice free relatives. The modality involved cannot be epistemic, as illustrated in section 2.1.2, (27a). Free choice free relatives, on the other hand, display epistemic readings in Romanian, as remarked in Caponigro \& Fălăuş (2017). Whenever there is no observable contrast between an FC-FR and an FC determiner plus a restrictive relative clause, it might turn out that one does not need to interpret the sentence epistemically. Taking the example in Caponigro \& Fălăuş (2017):

(44) Poliţia a arestat pe orice student care a protestat police.DEF has arrested PE ORICE student which has protested în clădirea asta ieri. in building.DEF this yesterday.

'The police arrested any student who protested in this building yesterday.'

It may be that an FC-FR counterpart, as the authors claim, is sensitive to the kind of information (or lack of information) that the speaker possesses regarding the actual students that got arrested, but this does not seem to be the case for (44). Rather, the interpretation of seems to depend on the enforcement of a temporary rule and is independent on whether the speaker witnessed the arrests or not. The next section offers an account of the link between events which is produced in subtrigged sentences. 


\section{Serial universality and the causal link}

The conclusions drawn in the previous section are: subtrigged sentences involve causal relations between events; these causal relations are independent of epistemic considerations (i.e., they may come about in cases of epistemic omniscience about what actually happened). One way of capturing this is to assume that subtrigged sentences are to be analyzed as a subcase of Rothstein's every time sentences or Ferreira's (2016) analysis of when clauses, that subcase in which Rothstein's matching function or Ferreira's relation $R$ exclusively means CAUSE. This, however proves to be incorrect, or insufficient, because we would expect to find the same interpretation in if clauses with an FCI in the antecedent. Yet, class II FCIs, as illustrated in section 1, are unacceptable in this environment. In the present terminology, FCIs in subtrigging environments produce serial universal interpretations, while FCIs in the antecedent of a conditional produce parallel universal interpretations.

I take this as evidence that, in if clauses the world and event variables co-vary one-to-one, an instance of $\mathrm{FC}_{\langle w, ! e, x\rangle}$ (see (15)). In the subtrigged case, what happens is that worlds, events and entities co-vary. This is compatible with Farkas's (2006) analysis of double indices, which will be further discussed in section 3.1 below. The further development proposed in this paper will be expounded in 3.2. By bringing in three types of variables instead of two, the present account also captures certain differences in interpretation (such as the one between if clauses and subtrigging). The analysis proposed here is one in which the fact that if clauses do not license tout is captured by the fact that in each world of the antecedent there is a unique event of a problem occurring, and the identity of this problem varies.

\subsection{Farkas (2006)}

\subsubsection{Marked indefinites}

Before presenting the formal implementation of undifferentiated choice items (UNIs) in Farkas (2006), this section introduces a number of marked indefinites which were analyzed in the literature as co-varying with entities, events or worlds. The aim is to draw attention to the existence of certain determiners that are specialized for expressing distributive event dependency, as well as world dependency. This empirical observation is not direct evidence for the account proposed here, involving three co-indexed variables, but is compatible with the view expressed in Farkas (2002; 2006) 
regarding the interpretation of marked indefinites. One way in which indefinites may be marked is by specifying the kind of variable they must be co-indexed with. One such kind of indefinite is that of distributive numeral DPs. These determiners associate with obligatorily distributive readings. Romanian marker câte is offered below as an illustration.

(45) a. Copiii au ascultat câte două cântece. children-DEF have listened DIST two songs

'The children listened to two songs each.'

b. Ion a ascultat câte două cântece pe zi Ion has listened DIST two songs on day

(cât a fost în vacanţă).

while has-3SG been in vacation

'John listened to two songs per day (while he was on vacation).'

c. \#Ion vrea să asculte câte două cântece.

John wants to listen DIST two songs

Many analyses that have been put forth for a number of similar distributive markers, those that seem to be licensed by both plural entities (the children in (45a) above) and plural events (each day in (45b) above) have assumed that their unifying licensing condition is some form of event dependency, with the apparent entity-dependency being a secondary effect. That is, distributive quantifiers map the entities in their restriction onto a set of events, and it is this event plurality that satisfies the selectional requirements of the distributive marker. For example, Cable (2013) proposes that nominal distributivity markers in Tlingit introduce a partition over an event-entity pair of variables, where each subevent in the cells of this partition corresponds to a participant of the cardinality specified by the distributive marker. Henderson $(2014 ; 2016)$ proposes that reduplicated numerals in Kaqchikel impose a postevaluation constraint (a postsupposition) on the event variable they are participants in. This event variable must be evaluation plural.

Russian wh-nibud indefinites, on the other hand, seem to display a hybrid behavior. Sometimes they pattern like distributive numerals, while other times they behave like FCIs. This seems to indicate that they are free to co-vary with any domain variable including intensional variables (see Pereltsvaig 2008; Yanovich 2005; Farkas 2015; Henderson 2016). Unlike other distributive markers (including câte (45), which is always extensional), they may interact with world variables; unlike FCIs, world dependency is not obligatory. In (46a) below, wh-nibud behaves like a distributive marker, while in(46b), it looks like an FCI (an existential one): 
(46) a. Každyj mal'čik vstretil kogo-nibud' iz svoix odnoklassnic. every boy met who-NIBUD' of his girl-classmate 'Every boy met one of his girl classmates.'

False if they all met the same classmate.

b. Petja xočet vstretit' kogo-nibud' iz svoix odnoklassnic.

Petja want to meet who-NIBUD' of his girl-classmate

'Petja wants to meet any of his girl classmates.'

\subsubsection{The account}

Farkas (2006) analyzes a class of marked determiners under the name of undifferentiated choice items (UCIs), bringing together NPIs, epistemic indefinites and universal free choice items. One of the main claims is that the distribution of alternatives does not necessarily apply at the level of worlds, but in some cases it can also apply at the level of situations. The interpretation of FCIs is assumed to involve a set of maximal mutually exclusive verifying alternatives. What this amounts to is that universal FCIs introduces a set of individual-situation pairs of alternatives, which are: maximal (they include all possible values of the relevant variable within the limits of salient contextual restrictions); mutually exclusive (all individual indices vary and all situation indices vary such that each alternative contrasts with all the others with respect to the values assigned to both individual and situation variables); verifying (each alternative makes $p$ true).

Alternatives are understood as possibilities (a set of assignment function-situation pairs $f, s$ such that $f(x, s)$ satisfies the descriptive content of the NP, where $x$ is the variable introduced by orice). Worlds are maximal situations. The relation situation-world is marked by the co-indexing of situations and the worlds that contain them (in the cases where situations are bound by worlds - the modal contexts). The set of alternatives provides a set of pairs of entities and situations $\left\langle v_{i}, s_{j}\right\rangle$. The indices are needed for the formulation of the mutual exclusivity condition:

(47) Mutual exclusivity

A set of alternatives $F$ is mutually exclusive iff for any two pairs $\left\langle v_{i}, s_{j}\right\rangle$ and $\left\langle v_{i^{\prime}}, s_{j^{\prime}}\right\rangle$ it provides, $i^{\prime} \neq i$ and $j^{\prime} \neq j$.

Moreover, unlike other undifferentiated items, orice has wide scope with respect to the (modal) operator that distributes the alternatives, which explains its apparent universal force:

(48) $x_{F}: \phi\left[\alpha O w^{\prime} \ldots x_{F} \ldots\right]$ 
In (48), $x_{F}$ is the variable introduced by orice, the subscript $F$ marks the set of individual-situation pairs of alternatives (constrained as in (47)), $O$ is the appropriate operator for distribution (modal verb, generic operator etc.). (49) defines what it means for an alternative to be verifying.

(49) $F$ verifies $\left[\delta \ldots x_{F} \ldots\right]$ relative to some $g, w$ such that $\llbracket \alpha \rrbracket^{w, g}=1$, iff for every $\left\langle f, s_{j}\right\rangle \in$ $F$ there is $\left\langle g^{\prime}, w_{j}\right\rangle \in G(x, w, g)$ such that $f(x)=g^{\prime}(x)$ and $s_{j} \leq w_{j}$

$G(x, w, g)$ is the set of evaluation parameters of $x$ in $\alpha$ (the expression) relative to $g, w$. The alternative set $F$ is construed in the following way: each alternative in $F$ provides an individual $a_{i}$ and a situation $s_{j}$ such that $a_{i}$ is a verifying value for $x$ in $\alpha\left(f(x)=g^{\prime}(x)\right)$ relative to some $w_{j}$ that contains $s_{j}$, where $\left\langle g^{\prime}, w_{j}\right\rangle$ is an evaluation parameter for $x$.

The mutual exclusivity condition, together with wide scope and maximality, derives the universal interpretation and the intensional distributivity effect of FCIs. Farkas's analysis of the interaction between orice and a possibility modal is provided below (where $D_{w}$ is the set of deontically accessible worlds to $w$, the actual world):

(50) a. Orice student poate pleca.

'Any student may leave.'

b. $x_{F}: \operatorname{student}\left(x_{F}\right)\left[\exists w_{j} \in D_{w}: \operatorname{leave}\left(x_{F}, w_{j}\right)\right]$

$F$ contains all entity-situation pairs in the model that satisfy the descriptive content of the NP (all situations containing a student). The truth conditions of (50) are:

(51) $\llbracket x: \operatorname{student}^{\prime}(x) \exists w^{\prime} x \in D_{w}$ : leave $\left(x, w^{\prime}\right) \rrbracket^{w, g}=1$ iff there is an $x$ version $g^{\prime}$ of $g$ such that $g^{\prime}(x) \in I_{w}\left(\right.$ student $\left.^{\prime}\right)$, and there is a $w^{\prime} \in D_{w}$ such that $\llbracket \operatorname{leave}^{\prime}(x) \rrbracket^{w^{\prime}, g^{\prime}}=1$

The $\left\langle f_{i}, s_{j}\right\rangle$ pairs that give values to $x$ here are worlds $w_{j}$ in $D_{w}$ and $x$-versions $g_{i}$ of $g$. The mutual exclusivity condition requires $i$ and $j$ to co-vary across the set of alternatives. The contribution of the subscript $F$ is the requirement below:

(52) For every $\left\langle f_{i}, s_{j}\right\rangle$ in $F$, there is an $x$-version $g_{i}$ of $g$, and a world $w_{j}$ in $D_{w}$ such that $s_{j} \leq w_{j}$, such that $w_{j}$ and $g_{i}$ can substitute for $w^{\prime}$ and $g^{\prime}$ in (51).

Together, (51) and (52) require each student to be part of a different deontically permissible world in which that student leaves. The following section offers an alternative option of capturing the same phenomenon, one that takes the co-indexation between indices to be an LF phenomenon. 


\subsection{2 Serial universality as causally related pairs of events}

\subsubsection{How event related readings come about}

Doetjes and Honcoop (1997) notice that, in the absence of a relative clause, only symmetric quantifiers have the ER reading. The property of interchange between NP and VP predicates is taken to be responsible for the reinterpretation of the quantifier from ranging over objects into ranging over event-object pairs. Quantifiers that are symmetric verify that $\mathrm{Q}(\mathrm{A})(\mathrm{B})$ $\equiv \mathrm{Q}(\mathrm{B})(\mathrm{A})$; e.g.: At least 4000 doctors are activists $\equiv$ At least 4000 activists are doctors. This allows for the eventive predicate in the Nuclear Scope (NS) to be mapped into the Restriction, as in (53b,c). Then a rule called Existential Disclosure applies, ${ }^{9}$ which allows for the quantifier to bind the event variable, as in (53d).

(53) 4000 ships passed through the lock.
a. $4000 x: \operatorname{ship}(x)(\exists e[$ passed-through-the-lock $(e, x)])$
b. $4000 x: \operatorname{ship}(x) \wedge \exists e[$ passed-through-the-lock $(e, x)])$
c. $4000\langle e, x\rangle: \operatorname{ship}(x) \wedge \exists e[$ passed-through-the-lock $(e, x)]$
d. $4000\langle e, x\rangle: \operatorname{ship}(x) \wedge$ passed-through-the-lock $(e, x)$

For nonsymmetric determiners, the analysis is the following. We start out with an independent event reading as in (54a). Then an anaphoric dependency is established, on a par with the binding of the pronoun in donkey sentences. The end result is given in (54c). See Doetjes \& Honcoop (1997) for the intermediary steps.

(54) Most ships that passed through the lock transported radioactive waste.

a. $\operatorname{MOST} x: \operatorname{ship}(x) \wedge \exists e[$ passed-through-the-lock $(e, x)]$ $\left(\exists e^{\prime}\left[\right.\right.$ transported-radioactive-waste $\left.\left(e^{\prime}, x\right)\right]$ )

b. $\operatorname{MOST} x: \operatorname{ship}(x) \wedge \exists e[$ passed-through-the-lock $(e, x)]$ (transported-radioactive-waste $\left(e^{\prime}, x\right)$ )

c. $\operatorname{MOST}\langle e, x\rangle: \operatorname{ship}(x) \wedge$ passed-through-the-lock $(e, x)$ (transported-radioactive-waste $\left(e^{\prime}, x\right)$ )

\subsubsection{Application to FCls}

Serial universal sentences will be analyzed in parallel to the proposal for most in Doetjes \& Honcoop (1997), presented in the previous subsection.

${ }^{9}$ This is a procedure of abstracting over a variable which was originally quantified over by an existential quantifier. See Dekker (1993) and Doetjes \& Honcoop (1997, 284). 
The ER readings of most above display a dependency between events in the relative clause and in the matrix clause. In the case of subtrigging, the dependency is an obligatory world-event-entity co-variation. In the case of FCIs, the connection between the two series of events relative clause and matrix) is not of co-temporality, but of non-accidentality (Dayal 1998; Jayez \& Tovena 2005, among others). For this reason, if it is counterintuitive to assume that there can be a non-accidental connection between the two, using the FCI is inappropriate:

$(55)^{?}$ By a strange twist of fate, any boy John passed by yesterday afternoon happened to be wearing a blue shirt.

Intuitively, there seems to be a causal link between the FC-events and the matrix events. In a sense, the relative clause events explain the matrix events. In the sentence below, John talks to students because they wanted to see him.

(56) John talked to any student who wanted to see him.

The assumption is that FCIs are grammaticalized as ranging over $\langle w, e, x\rangle$ triples and that serial universality is obtained by a causal link between restrictor and nucleus events.

(57) Any ship that passed through the lock was inspected by our security agents.

$\operatorname{FC}\langle w, e, x\rangle: \operatorname{ship}(x, w) \wedge$ passed-through-the-lock $(w, e, x)$

CAUSE $\left[w, e,\left(\operatorname{inspect}\left(w^{\prime}, e^{\prime}, x\right)\right)\right]$

The world variable is interpreted in a metaphysical modal base. The definition of CAUSE is taken from Kutschera (1993). See section 4 for further details. The relation between restrictor and nuclear scope is that of causation. ${ }^{10}$ The entry above is an option that all universal FCIs have. Nevertheless, in the case of parallel universality, a strategy parallel to (54) will be assumed.

(58) Any ship may pass through the lock.

$\mathrm{FC}\langle w, e, x\rangle: \diamond[\operatorname{ship}(x, w) \wedge$ pass-through-the-lock $(w, e, x)]$

The world variable is interpreted within a deontic modal base, which is supplied by the modal verb. Hence, there are no longer two series of worlds and events, one for the restriction and the other for NS, but only one -

${ }^{10}$ The interpretation of the causal dependency will be spelled out in more detail in the following section. 
the worlds and events of permission. Pragmatic strengthening can then apply to restrict the event variable to a single, unique event in each world. This is not an obligatory step, as in the following sentence, where it is reasonable to assume that there are multiple borrowing events in each permissible world:

(59) This year, you may borrow any book from the library.

The next section is dedicated to the interpretation of serial universality.

\subsection{Serial universality}

The linguistic phenomena presented in section 2 all involve constructions which relate pairs of events and which involve tense or aspect agreement or, optionally, some causal link between these events. Subtrigged sentences express non-accidental temporally restricted regularities. The relation between the two evens will be claimed to be strictly a causal relation between abstract events. Before proceeding to a definition of cause, I illustrate how the $T \times W$ branching framework intuitively works for subtrigged sentences.

(60) a. After the talk, John gladly answered any question.

b. Serial universality:

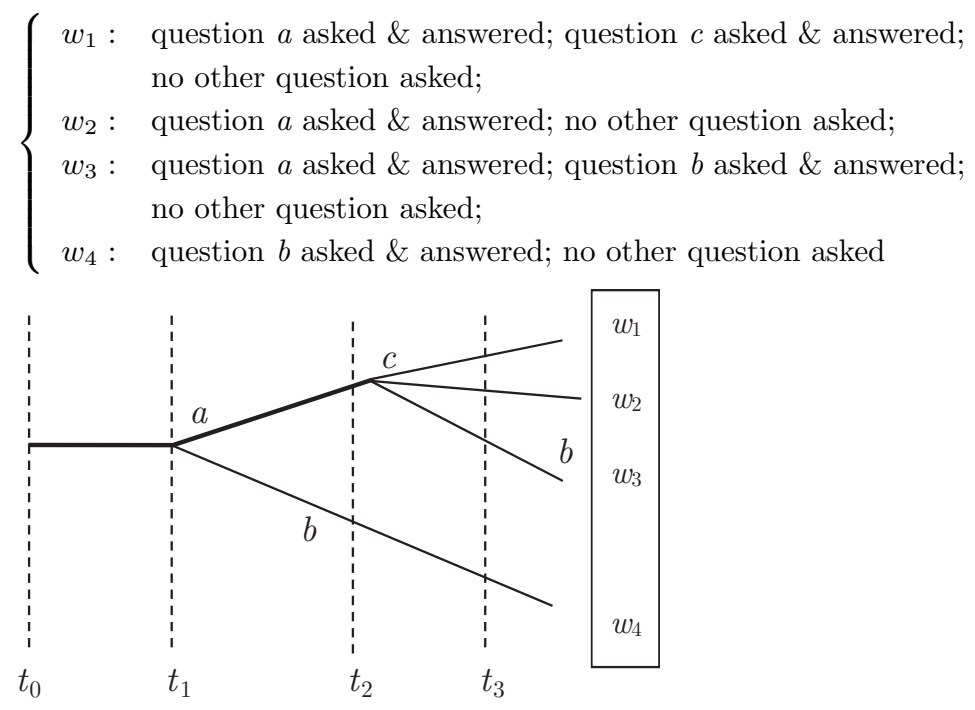

Taking the example above, given the fact that the noun question is eventive, the type of universality involved is serial, and the interpretation is 
that, within the given interval, whenever a questioning event happened it was necessarily followed by an answering event. In a time-world branching modal base as depicted in (60), necessity translates as the requirement that the answering should take place not in only one, but in all branches that extend some world where a question was asked. For instance, in the scenario above, question $a$ is asked at a certain point and produced a branching into $w_{4}$, in which $a$ was not asked, and $\left\{w_{1}, w_{2}, w_{3}\right\}$, in which it is asked, then something else triggers a further branching. Assume that no answering has taken place before this branching. Then, necessarily, the answering must take place on all of the branches that extended from the point in which $a$ was asked, that is, $w_{1}, w_{2}$ and $w_{3}$. Observe that serial universality necessarily involves domain shift (Jayez \& Tovena 2005) - the extension of the NP question varies across worlds. It has long been observed that contexts of serial universality are covert conditional structures (Quer 2000; Giannakidou 2001, among others). The proposal here is that this is indeed the case and that domain shift is triggered by the projection of alternatives within a metaphysical modal base, as understood in a non-deterministic modal framework with branching times.

\subsubsection{Causation: Kutschera (1993)}

Kutschera's layout may seem unnecessarily minute at first, compared with, for instance Kratzer's (1997) account of because sketched in section 2. However, given all the linguistic phenomena which seem to rely on links between events within episodic contexts, and all of the semantic differences between them, such a framework does not appear to be overly fine-grained. The distinction between concrete events, abstract events and state of affairs happens to have syntactic correlates. Neither because sentences, nor donkey "over cases" or generic sentences have the same range of application as FCI subtrigged sentences. The causal relation below is meant to capture serial universality as a relation between abstract events.

The theory of causation proposed in Kutschera (1993) is meant to capture causal relations between events (as opposed to states, facts, propositions etc.). These relations are understood as historical necessity within a non-deterministic metaphysical modal base. Worlds are modelled as rightbranching maximal segments within a tree universe, with a common beginning, the initial state. Worlds are assumed to be functions from time points into world states (WS) which are related via the successor relation. This means that all worlds have at leat one common state, the initial state, and, given the definition of the successor relation (see definition D1(1)), they are right-branching. That is, worlds are functions into the same set of 
WSs up to the point in which they cease to coincide and into necessarily distinct WSs from that point on.

Let us take an example of an implementation of a time-world branching framework independently needed to account for the ambiguity of a modal sentence such as (61) below:

(61) John might have won the game.

a. epistemic: the speaker is not sure whether John won

b. metphysical: at some point in the past it was possible for John to win, but he did not

The epistemic interpretation, as Condoravdi (2002) explains, is not rightward-branching. The epistemic agent considers at least two worlds, one in which John won at a previous time, and one in which he did not, but these two worlds coincide at the time of evaluation (now), i.e., for all the epistemic agent knows, either of these two worlds is the actual world at the time of evaluation. Interpretation (61b), on the other hand, comes about by backward-shifting the time of modal evaluation to a previous time when it was not yet decided whether John will win or not. From this perspective, there are two possible continuations, a world in which John wins and one in which he does not. These continuations are independent of the epistemic states of the speaker and are made up of non-overlapping world states. The world state corresponding to the time of utterance is on the branch corresponding to the non-winning scenario. A final remark is that the eventuality expressed by the verb in (61) on interpretation (b) is not stative. Substitutiong it for a state (John might have been sick) excludes interpretation (b).

The notion of causation that Kutschera (1993) intends to capture also relies on an interpretation of type (61b). Causes are events which were not bound to happen in all of the worlds accessible from the point of evaluation and which, in the worlds in which they do come about, guarantee the occurrence of the effect.

(62) An (abstract) event is a set $E$ of segments of worlds $w_{\tau}$ such that

a. $w_{\tau}, w_{\tau^{\prime}} \in E \rightarrow \tau=\tau^{\prime}$

b. $w_{\tau}, w_{\tau^{\prime}}^{\prime} \in E \wedge w_{\tau} \cap w_{\tau^{\prime}}^{\prime} \neq \emptyset \rightarrow \tau_{1}=\tau_{1}^{\prime}$

In the definition above, $\tau$ and $\tau^{\prime}$ are time intervals. In each world $w$, each event $w_{\tau}$ has a well-defined beginning (the first point of $\tau$, marked as $\tau_{1}$ ) and a well-defined ending. Condition (62a) states that each event occurs at least once in every world. Condition (62b) states that if some event $E$ 
is instantiated in two worlds, $w$ and $w^{\prime}$, at intervals $\tau$ and $\tau^{\prime}$ respectively, such that $w$ and $w^{\prime}$ are identical at some point during their instantiation of $E$, then $E$ has the same beginning in these worlds. This is an extension of the rightward branching property of worlds as expressed within the domain of events.

The definition captures the idea that an event may take place at different times and under different circumstances in different worlds. The requirement $w_{\tau}, w_{\tau^{\prime}}^{\prime} \in E$ restricts the application of (b) to cases in which the event was completed in both $w$ and $w^{\prime}$, ruling out cases in which the event was only initiated but not completed in one of the worlds.

States of affairs (SAs) are sets of pairs of worlds and times. SAs are callled eventlike if there is some $E$ such that for all pairs $\langle w, t\rangle$ in their denotation, there is some interval $\tau$ such that $t \in \tau$ and $w_{\tau} \in E$.

(63) Time-dependent necessity (Kutschera's D8):

$N(w, t, X):=W^{w(t)} \subset X$

State of affairs $X$ is necessary from the standpoint of the world state $w(t)$ iff $X$ holds in $t$ in all worlds coinciding with $w$ in $t$. For events, timedependent necessity amounts to the equivalence below:

(64) $N(w, t, E) \equiv W^{w(t)} \subset\left\{w^{\prime}: \exists \tau\left(w_{\tau} \in E \wedge t \in \tau\right)\right\}$

Event $E$ is necessary at $t$ in $w$ iff it occurs in all worlds which coincide with $w$ at $t$.

(65) a. The state of affairs that E occurs:

$$
E^{0}:=\left\{w: \exists \tau\left(w_{\tau} \in E\right)\right\}
$$

b. $E$ is determined $(D)$ in $w, t$ :

$D(E, w, t):=W^{w(t)} \subset E^{0}$

c. $E$ is determined from its beginning $(D B)$ in $w$ :

$D B(E, w):=\exists \tau\left(w_{\tau} \in E \wedge D\left(E, w, \tau_{1}\right)\right)$

Causal relations between events are defined as follows:

(66) $C A U S E\left(w, E, E^{\prime}\right):=\exists \tau\left(w_{\tau} \in E \wedge \forall w^{\prime} \forall \tau^{\prime}\left(w^{\prime} \in W^{w\left(\tau_{1}\right)} \wedge w_{\tau^{\prime}}^{\prime} \in E \rightarrow\right.\right.$ $D B\left(E^{\prime}, w^{\prime}\right) \wedge \neg D\left(E^{\prime}, w^{\prime}, \tau_{1}^{\prime}\right)$

In words, (66) says that in $w, E$ causes $E^{\prime}$ iff $E$ occurs in $w$ at interval $\tau$ and in all worlds $w^{\prime}$ coinciding with $w$ at the beginning of $E$ in which $E$ also holds in some interval $\tau^{\prime}$, the occurrence of $E^{\prime}$ is determined from its 
beginning in $w^{\prime}$ and is not determined in any $w^{\prime}$ at the point in time at which $E$ begins.

Taking the first line, the worlds $w^{\prime}$ are those in which the cause $E$ holds at some interval $\tau^{\prime}$ and, moreover, whose beginning coincides with the beginning of $E$ in the world of evaluation $w$. That is, we are considering worlds which coincide with $w$ up to and including the beginning of $E$. The cause began in the same way and was completed in each of these worlds, but $E$ may have taken longer or other circumstances may have happened differently in each of these worlds after this point.

The two conditions on the second line capture the asymmetry between cause $(\mathrm{E})$ and effect $\left(E^{\prime}\right)$. The effect is determined from the beginning in all worlds $w^{\prime}$ in which the cause takes place, but it is not determined in all the worlds which coincide at the point where the cause began. This is because deciding whether an event is determined from the vantage point of $w^{\prime}$, according to definition (b), requires one to look at all the worlds which coincide with $w^{\prime}$ up to that point, which are not only $E$-worlds. This means that the cause $E$ is not determined at $\tau_{1}$ (it need not have occurred).

The time $\tau_{1}$ and world $w$ of evaluation determine the sets of worlds taken into consideration. The definition says that, in view of the circumstances obtaining in $w$ and $\tau_{1}, E^{\prime}$ must occur if $E$ does, no matter how the world goes on. It does not make the stronger claim that $E$ will always be followed by events of the type $E^{\prime}$. For example, the explosion of a bomb is the cause of John's death even if the bomb, if it had exploded later on, when John was not around, would not have killed him.

\subsubsection{Concrete and abstract events, states of affairs}

The notion of events E defined as a set of world segments which occur only once in each world is a notion of particular, but abstract events. By contrast, types of events are not particular and abstract, since they can occur multiple times in the same world. Concrete events are indexed to the world in which they occur $\left(E_{w}\right)$. The cause relation can range over such concrete events. For example, if $E_{w}$ is the explosion of the bomb exactly as it occurred in $w$ and $E_{w}^{\prime}$ is John's death exactly as it happened in $w$, then one can say that the explosion of the bomb caused John's death (i.e., $\operatorname{CAUSE}\left(E_{w}, E_{w}^{\prime}\right)$ holds), but not that the fact that the bomb exploded is the cause of the fact that John died (i.e., $C A U S E\left(E, E^{\prime}\right)$ does not hold).

This typology allows for a constrast between causal links within subtrigged sentences as opposed to conditional relations. Conditional sentences, in Kutschera's framework, do not involve CAUSE, since conditional 
relations do not only hold between states, but also between types of events (which may occur more than once in the same world) as well as states. For an implementation of conditional relations, see section VIII. What is important for the present purposes is that Kratzer's notion of exemplifications of states of affairs is compatible with a conditional relation, not with a causal one, regardless of the labels simple cause and causal explanation. The connection between the two eventualities in because clauses is only apparently a causal one, and this impression of causality disappears if any of the two eventualities is a state (as in I went to the pageant because the principal is sick).

The main point to be made regarding subtrigged sentences is that a temporally bound regularity is involved, but this is the outcome of two concurrent factors: the cause relations between events (not event types) and the semantics of free choice, which requires the variable introduced by the free choice determiner to range over all possible values.

Importantly, FC determiners like French tout are not licensed inside the antecedent of a conditional, unlike English any (as the well-formed translation indicates). This would be indeed puzzling if subtrigging were simply described as a covert conditional structure, without further qualifications.

\section{Conclusions}

Taking stock, I have opted for a syntax-semantics based account of the correlation between entities, events and worlds due to various reasons, among which the surprising difference between conditionals and subtrigged sentences, as well as the less striking difference between FC-FRs and subtrigged sentences. From this I concluded that maximality over individuals may be taken as an evaluation constraint of universal FCI crosslinguistically, but co-variation with events is syntactically constrained on a par with event-related readings of non-symmetrical quantifiers.

Secondly, I have opted for a stronger link between events in subtrigged clauses than a conditional or because clause might allow due to the fact that the data suggest the link between events is never actually epistemic and that the perfective past matching constraint precludes configurations such as a state of affairs being an explanation for some other state of affairs (or any combination which includes at least one state, state of affairs or proposition). Rather, both the relative clause and the matrix clause verbs express events, with the relative clause event not being guaranteed to happen, and the matrix clause event being guaranteed as soon as the 
relative clause event takes place. That is a causal relation, one which in the case of subtrigging holds between abstract events (notated with capital letters $E, E^{\prime}$, etc.) as opposed to concrete events such as the first climbing of Mount Everest (notated with $e, e^{\prime}$, etc.) These abstract events co-vary with worlds and entities, but for a given entity and world, they are unique and cause a unique effect.

There are many problems left open, among which the most interesting would be to extend the account to other environments available to all universal FCIs (among which generics, dispositionals, comparatives). These FC licensing environments may not be called serial universality yet one may want to apply the same idea as exposed here, the co-variation between three types (instead of only two types) of variables, to these environments as well. In any case, the novelty of the present approach may be the semantic and syntactic distinction between inter-clausal and innerclausal phenomena, as well as the distinction between events proper and everything else (be they states, states of affairs, propositions, etc.), which may prove relevant to more than only one particular semantic particularity (subtrigging, in the present case).

\section{Acknowledgements}

This work is part of the program "Investissements d'Avenir", overseen by the French National Research Agency, ANR-10-LABX-0083.

\section{References}

Barwise, Jon and Robin Cooper. 1981. Generalized quantifiers and natural language. Linguistics and Philosophy 4. 159-219.

Boolos, George. 1981. For every A there is a B. Linguistic Inquiry 12. 465-467.

Cable, Seth. 2013. Distributive numerals and distance distributivity in Tlingit (and beyond). Lingbuzz/001814.

Caponigro, Ivano and Anamaria Fălăuş. 2017. Free choice free relative clauses in Italian and Romanian. Natural Language and Linguistic Theory 36. 1-41.

Chierchia, Gennaro. 2013. Free choice nominals and free choice disjunction: The Identity Thesis. In Fălăuş (2013, 50-87).

Condoravdi, Cleo. 2002. Temporal interpretation of modals: Modals for the present and for the past. In D. Beaver, L. D. C. Martinez, B. Z. Clark and S. Kaufmann (eds.) The construction of meaning. Stanford: CSLI Publications. 1-30.

Davidson, Donald. 1967. Causal relations. Journal of Philosophy 64. 691-703.

Dayal, Veneeta. 1998. Any as inherently modal. Linguistics and Philosophy 21. 433-476. 
Dayal, Veneeta. 2013. A viability constraint on alternatives for free choice. In Fălăuş (2013, 88-122).

Dekker, Paul. 1993. Existential disclosure. Linguistics and Philosophy 16. 561-587.

Deo, Ashwini. 2009. Unifying the imperfective and the progressive: Partitions as quantificational domains. Linguistics and Philosophy 32. 475-521.

Doetjes, Jenny and Martin Honcoop. 1997. The semantics of event-related readings: A case for pair quantification. In A. Szabolcsi (ed.) Ways of scope taking (SLAP 65). Dordrecht: Kluwer. 263-310.

Ebert, Cornelia and Stefan Hinterwimmer. 2010. Quantificational variability effects with plural definites: Quantification over individuals or situations? Journal of Semantics 27. 139-176.

Fălăuş, Anamaria (ed.). 2013. Alternatives in semantics. London: Palgrave Macmillan.

Farkas, Donka. 2002. Varieties of indefinites. In B. Jackson (ed.) Proceedings of the 12th Semantics and Linguistic Theory Conference (SALT 12). Ithaca, NY: Linguistic Society of America and Cornell Linguistics Circle, Cornell University. 59-83.

Farkas, Donka. 2006. Free choice in Romanian. In B. J. Birner and G. Ward (eds.) Drawing the boundaries of meaning, neo-Gricean studies in pragmatics and semantics in honor of Laurence R. Horn. Amsterdam \& Philadelphia: John Benjamins. 71-94.

Farkas, Donka. 2015. Dependent indefinites revisited. Workshop on Distributivity, Paris.

Ferreira, Marcelo. 2016. The semantic ingredients of imperfectivity in progressives, habituals and counterfactuals. Natural Language Semantics 24. 53-397.

Giannakidou, Anastasia. 2001. The meaning of free choice. Linguistics and Philosophy 24. 659-735.

Giannakidou, Anastasia and Lisa Lai-Shen Cheng. 2006. (in)definiteness, polarity, and the role of wh-morphology in free choice. Journal of Semantics 23. 135-183.

Henderson, Robert. 2014. Dependent indefinites and their post-suppositions. Semantics \& Pragmatics 7. 1-58.

Henderson, Robert. 2016. Variation in dependent indefinites. Workshop on Distributivity, Paris. https://tinyurl.com/yd6qncet

Hinterwimmer, Stefan. 2008. Q-adverbs as selective binders: The quantificational variability of free relatives and definite DPs. Berlin \& New York: Mouton de Gruyter.

Horn, Laurence R. 2000. Pick a theory (not just any theory): Indiscriminatives and the Free Choice indefinite. In L. R. Horn and Y. Kato (eds.) Negation and polarity. Syntactic and semantic perspectives. Oxford: Oxford University Press. 147-192.

Horn, Laurence. R. 2005. Airport '86 revisited: Toward a unified indefinite any. In G. N. Carlson and F. J. Pelletier (eds.) Reference and quantification: The Partee effect. Palo Alto, CA: CSLI Publications. 179-205.

Jayez, Jayez and Lucia M. Tovena. 2005. Free-choiceness and non individuation. Linguistics and Philosophy 28. 1-71.

Jayez, Jayez and Lucia M. Tovena. 2006. Epistemic determiners. Journal of Semantics 23. $217-250$.

Kadmon, Nirit and Fred Landman. 1993. Any. Linguistics and Philosophy 16. 353-422.

Kratzer, Angelika. 1997. Scope or pseudo-scope? Are there wide scope indefinites? https://www.semanticsarchive.net/Archive/DFjNjM5M/Scope.or.Pseudoscope.pdf 
Krifka, Manfred. 1990. Four thousand ships passed through the lock: Object-induced measure functions on events. Linguistics and Philosophy 13. 487-519.

Kutschera, Franz von. 1993. Causation. Journal of Philosophical Logic 22. 563-588.

LeGrand, Jean Ehrenkranz. 1975. Or and any: The syntax and semantics of two logical operators. Doctoral dissertation. University of Chicago.

Lenci, Alessandro and Pier Marco Bertinetto. 2000. Aspect, adverbs, and events: Habituality vs. perfectivity. In J. Higginbotham, F. Pianesi and A.Varzi (eds.) Speaking of events. Oxford: Oxford University Press. 245-287.

Lewis, David. 1975. Adverbs of quantification. In E. L. Keenan (ed.) Formal semantics of natural language. Cambridge: Cambridge University Press. 3-15.

Menendez-Benito, Paula. 2005. The grammar of choice. Doctoral dissertation. University of Massachusetts, Amherst.

Nakanishi, Kimiko. 2017. Free choice wh-demo in Japanese: Universality, vagueness, and iterativity. Workshop on Distributivity, Paris.

Pereltsvaig, Asya. 2008. Russian nibud'-series as markers of co-variation. In N. Abner and J. Bishop (eds.) Proceedings of the 27th West Coast Conference on Formal Linguistics. Somerville, MA: Cascadilla Proceedings Project. 370-378.

Quer, José. 1998. Mood at the interface. The Hague: Holland Academic Graphics.

Quer, Josep. 2000. Licensing free choice items in hostile environments: The role of aspect and mood. Manuscript. University of Amsterdam.

Rothstein, Susan. 1995. Adverbial quantification over events. Natural Language Semantics 3. $1-31$.

Sæbø, Kjell Johan. 2001. The semantics of Scandinavian free choice items. Linguistics and Philosophy 24. 737-787.

Tredinnick, Victoria Ann. 2005. On the semantics of free relatives with -ever. Doctoral dissertation. University of Pennsylvania.

Yanovich, Igor. 2005. Choice functional series of indefinite pronouns and Hamblin semantics. In E. Georgala and J. Howell (eds.) Proceedings of SALT XV. Ithaca, NY: CLC Publications, Cornell University. 309-326. 
